\title{
微小水滴の過冷却とその凍結に関する実験
}

\author{
佐野惈・藤谷義保・川瀬健

\section{An Experiment on the Supercooling of Water-Droplets Containing Foreign Solid Particles}

\author{
By I. Sano, Y. Fujitani and K. Kawase \\ Chemical Institute, Faculty of Science, Nagoya University, Nagoya. \\ (Manuscript received 8 March, 1958)
}

\begin{abstract}
A number of water-droplets, uniform in size at $1.0,0.6,0.3$ or $0.2 \mathrm{~mm}$ diameter, were prepared from water holding powder suspended as well as water having no addition, by electrical atomization, on a paraffin-covered glass-plate. This glass-plate was placed horizontally in a flat case tightly made of two brass-plates together with a rubber-frame between, and was cooled at various temperatures down to $-30^{\circ} \mathrm{C}$ in a cryostat. Following this, the plate was quickly taken out from the case, and the droplets which had frozen were counted without delay in a low-temperature chamber, using a phase-contrast microscope and, on occasions, by the naked eye.

The powder-materials suspended were iodides of silver, mercury and lead, and further, oxides of copper, cadmium and zinc. As for lead iodide, it was the most soluble of the materials examined, so that an investigation into the influence of aging of the powder in suspended state upon the supercooling phenomenon was carried out in the following manner; the suspension of lead iodide was, after its production, allowed to stand in a closed vessel with frequent stirring for the periods of 0,2 and 8 days at $5^{\circ} \mathrm{C}$ or thereabouts, and these three samplings dispersed each to droplets by the same method as with the other materials.

The results are roughly as follows:

1) The smaller the droplets, the more likely they are to exhibit supercooling, the finding being the same in both the absence and presence of solid particles in water, and there appears to exist a linear relation between the logarithm of droplet-diameter and the freezing-temperature.

2) Of the materials tested, silver iodide is most effective in solidifying water under supercooled condition, and its effectiveness goes up, though slightly, as the amount added to water is increased; lead iodide deteriolates considerably on account of its solubility, it being left to itself in suspended state.

3) The following equation

$$
\ln \{x /(100-x)\}=k \cdot\left(\theta-\theta^{\prime}\right)
$$

is presented as giving the fraction $(x \%)$ of droplets frozen at a supercooling $\left(\theta^{\circ} \mathrm{C}\right.$, expressed in terms of the lowering from $0^{\circ} \mathrm{C}$ ), $k$ being a constant depending on the conditions of experiment such as the droplet-size, the nature and amount of the powder suspended, etc. and $\theta^{\prime}$ the supercooling at which $x=50$.
\end{abstract}

序言

過冷却の雲に沃化銀气の他(1)の煙を混合すると これらの粒子が核として作用し氷晶为形成され る。この事実は人工降雨の実際に応用されている 処であるが，核作用の機構乃至水晶形成の過程に ついては今日でも知見不足で議論が決していない 点子多く, 例觉ば過冷却の雲粒から水蒸気が核粒 子上に卓華して，直接，水晶为形成されるとする
所謂昇華核の説(2)が行なわ秃ている一方，水蒸気 が核粒子上飞吸着されて過冷却の水分子層を生じ， これが谏結して氷晶に化するとする所謂凍結核の 説(3) る唱光られている等*はこれがためである。 篻者等 ${ }^{(4)}$ 快, 從来, 種々の化学物質の我晶核々

* 実際には両者恐らく並発するらしい(小林禎作 (1956)：Diffusion Cloud Chamber による雪，氷晶の 生成機棈の研究 (序報), 低温科学, A, 15, 1 11)。 
てての有效性について赛験的研究を行ない，その 結果を昇華核説にもとづき解釈してきたが，今回， 凍結核説を検討する目的の下に先ず予備的の実験 を試みたのでその概要をここに報告する。

な物，水の過冷却の現象は古く Fahrenheit (1724) により記載されて以来，多くの人々の関心 を集めてきたるのであるが，その中，過冷却微小 水滴の涷結についてはこれを特に気象学的見地か ら取り上げた研究がわが国でも最近一，二報告さ れている(5)。

\section{実験方法}

下端为毛細管（内径，約 $0.1 \mathrm{~mm}$ ) になっている ガラス管に水或は沃化銀，沃化鉛，酸化銅または 酸化亜鉛等の懸濁液*（濃度： $10^{-4} \sim 10^{-5} \mathrm{~g} / \mathrm{cc}$ ）を 入れてこれを垂直に固定し，ネオントランスの二 次側の一方の極を液中に，他方をアース（銅板： $\left.10 \mathrm{~cm}^{2}\right)$ につなぎ，毛細管の下端と銅板を $20 \mathrm{~cm}$ 前後離してこの間に電圧 $(2,000 \sim 6,000$ ヴォルト)

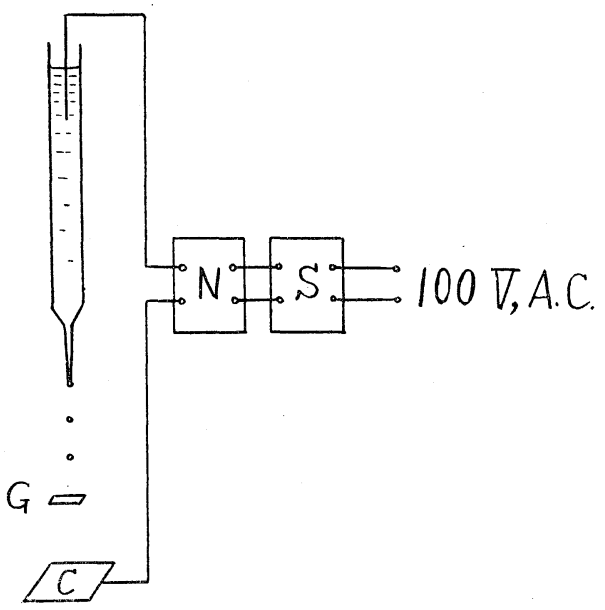

Fig. 1 Device for preparing liquid-droplets of uniform size.

$\mathrm{C}$ : copper-plate $\mathrm{N}$ : neon-transformer

G: glass-plate S: sliding voltstat

*乳鉢で十分にすりつぶした粉体を水中に浮游させ たもので, 粒子が溶解度をもつ場合には一部分子状に溶 解していることになる。試料はすべて化学用純品であ る。䀣濁液の濃度は最初水に加光た粉体の全量に関し て表わしてあるが，ただ沃化鉛の場合には多少溶解度が あるので先ずその飽和水溶液をつくり，これに粉体が加 㝋られている。
をかけると粒度の殆ど揃った液滴が落下する（第 1 図)。液滴の大きさは電圧が高い程小さい( ${ }^{(6)}$ 今回の実験では直径 $0.2 \sim 1.1 \mathrm{~mm}$ のものが用い て山る。このよ5にして得られる液滴約 30 個を, 蒸溜したパラフィンを塗った，ガラス板の上に受 けて試料とし，これを冷却用セル（第 2 図）の中

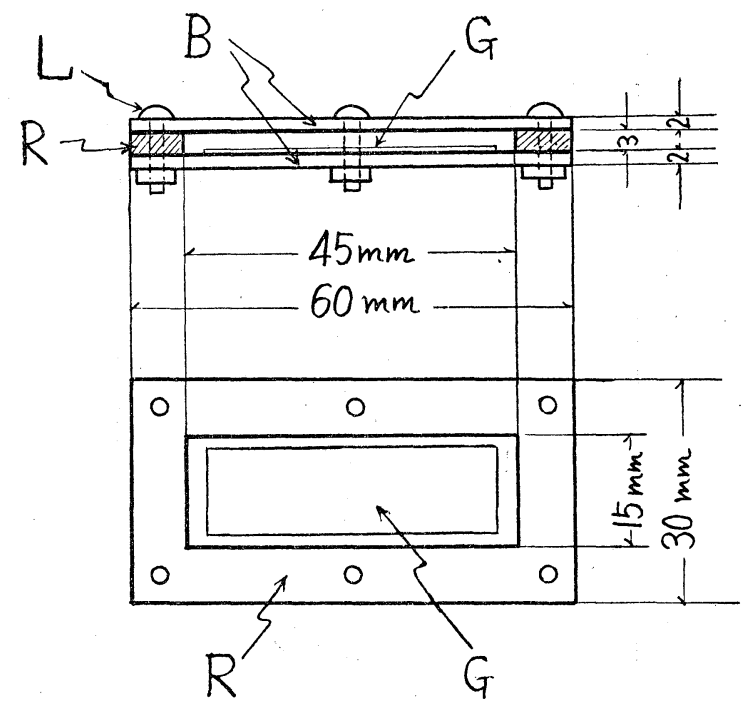

Fig. 2. Vessel for housing a droplets-supporting glass-plate. The upper half shows the elevation of the assemblage and the lower half its plan without the cover.
B: brass-plate
L: bolt
G: glass-plate
$\mathrm{R}$ : rubber-sheet

に密閉する。セルは図の如く四角いゴム枠をその 上下から 2 枚の真鍮板でさしはさみ，ボルトでし めてつくり岕げる，大きさ $60 \mathrm{~mm} \times 30 \mathrm{~mm} \times$ $7 \mathrm{~mm}$ の平たい箱形のもので, ゴム枠の中に前記 液滴附きのガラス板を置くようになっている。

試料を納めたセルを，次に，ドライアイスで冷 却して $0^{\circ} \mathrm{C}$ 以下の所定の温度に保ってある塩化力 ルシウムの飽和水溶液中に水平に浸乙（第 3 図）, 所定の時間——今回はすべて10分とした——間 放置した後，七ルを液から取り出し，ただちにガ ラス板をはずして手早くその上の液滴を肉眼また は低倍率 $(\times 50)$ の位相差顕微鏡で 観察し，その 何\%が凍結しているかを勘定する。凍結した液滴 は白濁して見えるので判別することができる。以 上の操作はすべて低温室内で行なった。 


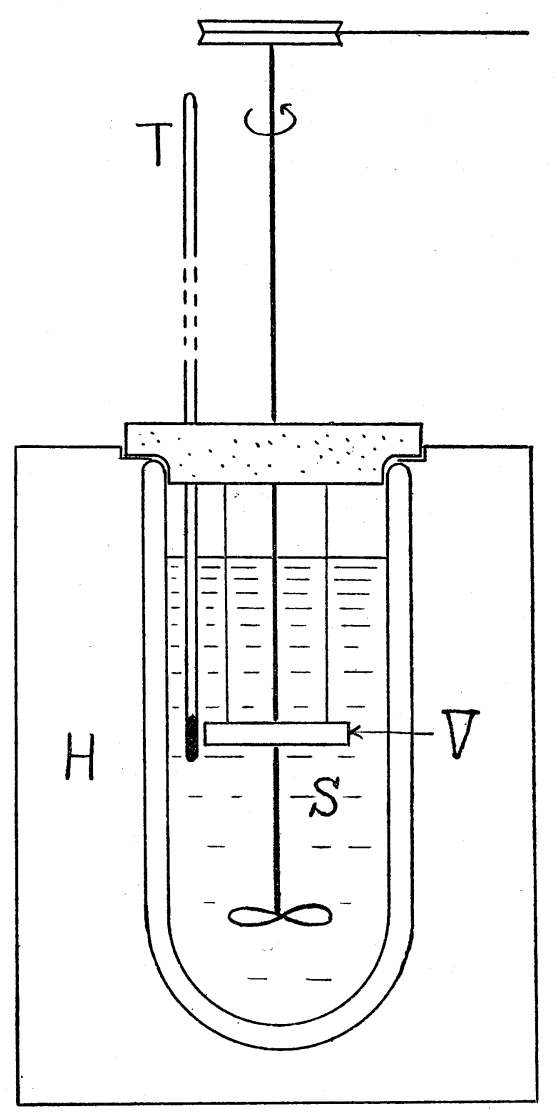

Fig. 3. Cooling equipment.

$\mathrm{H}$ : heat-insulating wooden box

S: solution of calcium chloride

$\mathrm{T}$ : thermometer

$\mathrm{V}$ : vessel carrying a droplets-supporting glass-plate

\section{実験結果とその考察}

実験結果は第 4〜7図の如くで，これらの場合， 横軸は温度 $\left({ }^{\circ} \mathrm{C}\right)$ を表わし, 縱軸は凍結率（粒子 数\%) である。第 5 図は沃化銀懸濁液に対する凍 結曲線（懸濁液濃度：10 $10^{-4}, 10^{-5}$ 及び $10^{-6} \mathrm{~g} / \mathrm{cc}$; 液滴直径：1.1〜0.9，0.7〜0.5 及び $0.3 \sim 0.1 \mathrm{~mm}$ ) で，純水に対する凍結曲線(第 4 図）と比べると沃 化銀粒子の存在する場合には水滴の過冷却度が大 幅に弱められ，凍結し易くなることがうかがわれ る。第 6 及び 7 図はそれぞれ酸化物㲘濁液の場合 (濃度： $10^{-4} \sim 10^{-5} \mathrm{~g} / \mathrm{cc}$; 直径： $0.7 \sim 0.5 \mathrm{~mm}$ ) 及び 沃化物椹濁液の場合（濃度： $10^{-4} \sim 10^{-5} \mathrm{~g} / \mathrm{cc}^{*}$; 直 径: 1.1〜0.9 mm) で, 後者には比較のために沃化

* 但し，沃化鉛については前出の脚註参照。
銀懸濁液に関する凍結曲線(第 5 図)の一部が示め してある。

今回実験した酸化物，沃化物の中で，沃化鉛は 水に対し或る程度の溶解性をるっているのでその 影響を知るために懸濁液の生成直後, 2 日及び 8 日放置後等の場合について実験した。その結果が 第 7 図中の $0,2,8$ 等と附記されている曲線で, 摹濁液を放置するにつれ明かに過冷却度が大きく なっているが，この理由については何等かの原因

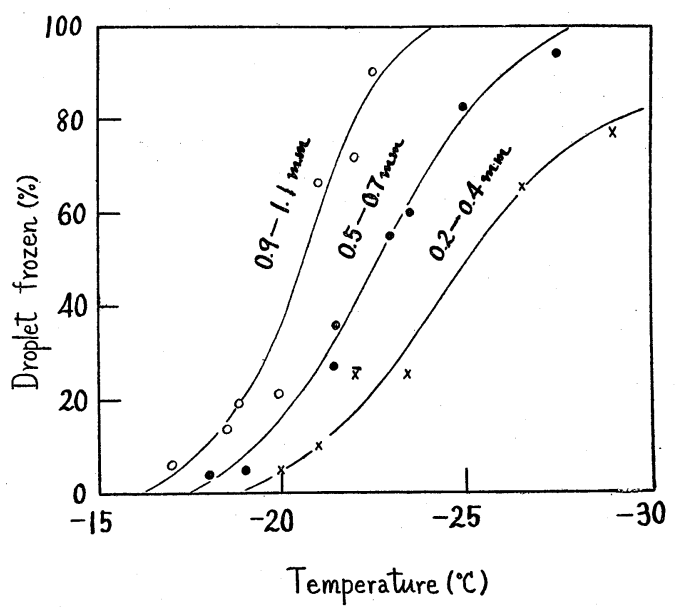

Fig. 4. Frequency of freezing plotted against temperature of cooling for droplets of water of several values of diameter.

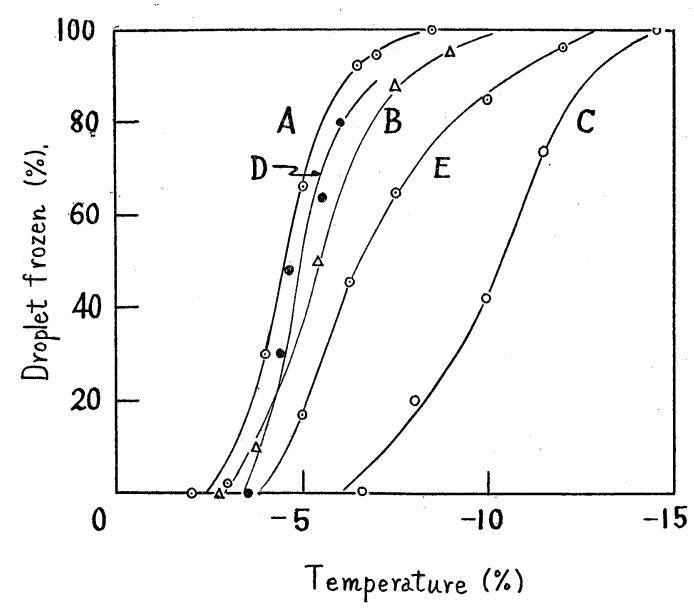

Fig. 5. Frequency of freezing plotted against temperature of cooling for droplets of suspension of silver iodide. A: droplet-diameter, 1.1$0.9 \mathrm{~mm}$ and suspension-concentration, $10^{-4} \mathrm{~g} / \mathrm{cc}$; B: $\quad 0.7-0.5 \mathrm{~mm}$ and $10^{-4} \mathrm{~g} / \mathrm{cc} ; \quad \mathrm{C}: \quad 0.3-0.1 \mathrm{~mm}$ and $10^{-4} \mathrm{~g} / \mathrm{cc} ; \quad \mathrm{D}: 1.1-0.9 \mathrm{~mm}$ and $10^{-5} \mathrm{~g} / \mathrm{cc}$; E: $\quad 1.1-0.9 \mathrm{~mm}$ and $10^{-6} \mathrm{~g} / \mathrm{cc}$. 


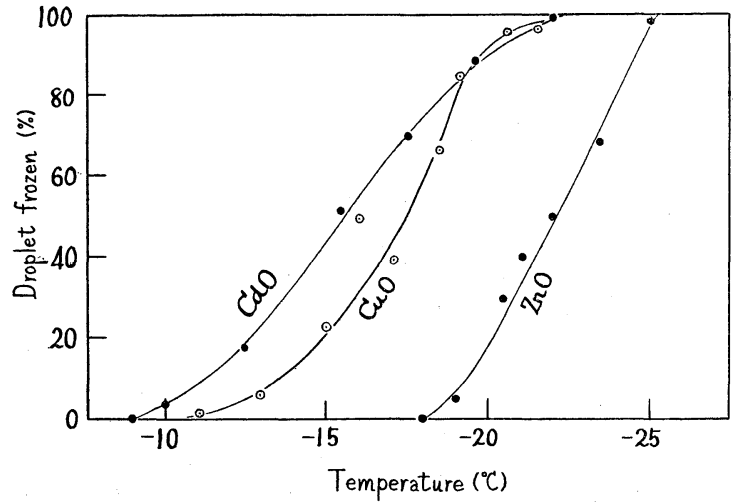

Fig. 6. Frequency of freezing plotted against temperature of cooling for droplets (diam., $0.7-0.5 \mathrm{~mm}$ )

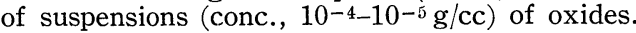

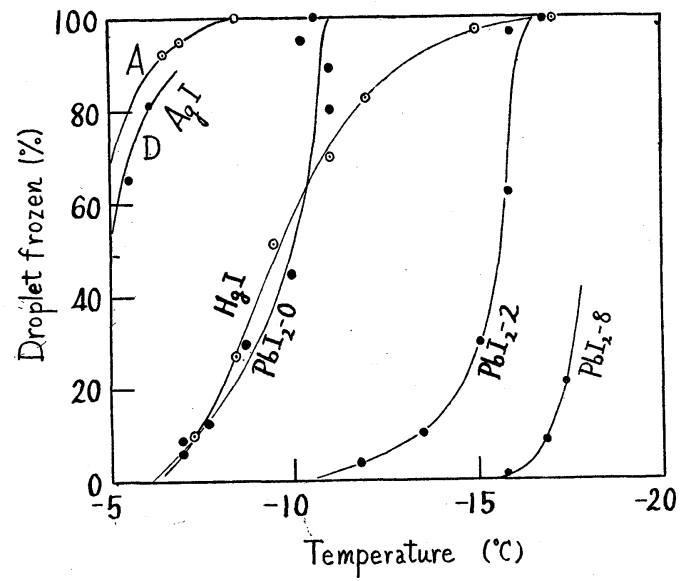

Fig. 7. Frequency of freezing plotted against temperature of cooling for droplets (diam., 1.1-0.9 $\mathrm{mm}$ ) of suspensions (conc., $10^{-4}-10^{-5} \mathrm{~g} / \mathrm{cc}$ ) of iodides.
例光ば Kelvin の理論に従い，粒子表面の 中，曲率の大きい部分程よく溶け出る等—— よって懸濁沃化鉛粒子の表面が変化し，従って 凍結作用が衰光てくるためであろらと想像され るが，八ッキリしたことは，現在の処，不明で ある。な招，沃化鉛に限らずその他の懸濁液の 場合でる放置するにつれて多かれ少なかれ凝結 作用の低下する傾向が認められた。

次に第 4 及び 5 図中の各凍結曲線から凍結率

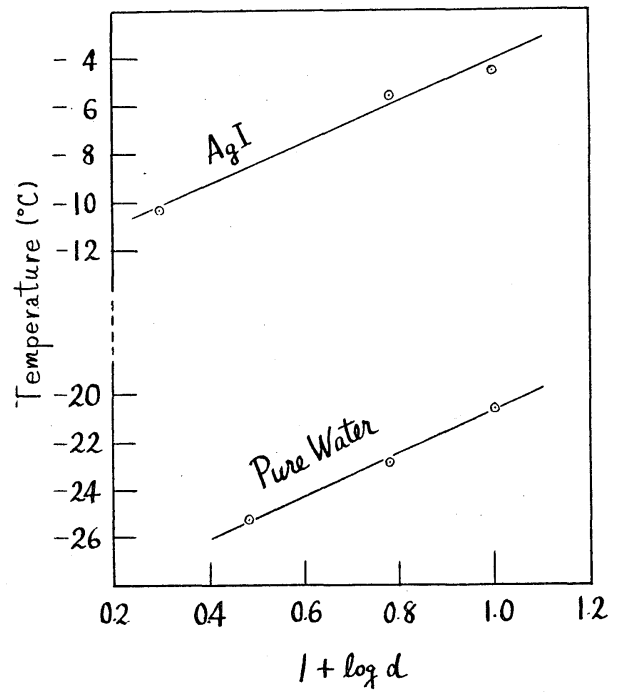

Fig. 8. Dependence of freezing-temperature on droplet-diameter (d: diameter in $\mathrm{mm}$ ). The silver iodide line was drawn, using the values read from the curves $\mathrm{A}, \mathrm{B}$ and $\mathrm{C}$ in Fig. 5 .

Table 1. Effect of the foreign solid-particle suspended in water-droplet upon its supercooling.

\begin{tabular}{|c|c|c|c|c|c|c|c|}
\hline \multicolumn{4}{|c|}{ Suspended Matter } & \multirow{3}{*}{$\begin{array}{l}\text { Aging prior } \\
\text { to droplet } \\
\text { production } \\
\text { (day) }\end{array}$} & \multirow{2}{*}{\multicolumn{3}{|c|}{\begin{tabular}{|l} 
Mean freezing temperature $\left({ }^{\circ} \mathrm{C}\right)$ \\
Mean diam. of droplet $(\mathrm{mm})$
\end{tabular}}} \\
\hline \multirow{2}{*}{$\begin{array}{l}\text { Chemical } \\
\text { formula }\end{array}$} & \multirow{2}{*}{$\begin{array}{l}\text { Solubility in } \\
\text { water } \\
\text { (g/cc, water) }\end{array}$} & \multirow{2}{*}{$\begin{array}{c}\text { Crystal system } \\
\text { in } \\
\text { Crystallization }\end{array}$} & \multirow{2}{*}{$\begin{array}{c}\text { Suspended } \\
\text { amount } \\
\text { (g/cc, water) }\end{array}$} & & & & \\
\hline & & & & & 1.0 & 0.6 & $0.3,0.2$ \\
\hline \multicolumn{4}{|c|}{ None (Water alone) } & 0 & -20.6 & -22.8 & -25.1 \\
\hline $\mathrm{AgI}$ & $\begin{array}{l}1 \times 10^{-9}\left(13^{\circ} \mathrm{C}\right) \\
2 \times 10^{-9}\left(25^{\circ} \mathrm{C}\right)\end{array}$ & Hexagonal & $\begin{array}{l}10^{-4} \\
10^{-5} \\
10^{-6}\end{array}$ & 0 & $\begin{array}{l}-4.5 \\
-4.9 \\
-6.5\end{array}$ & $\underline{-5.6}$ & $\underline{-10.3}$ \\
\hline $\mathrm{HgI}$ & $2 \times 10^{-10}\left(25^{\circ} \mathrm{C}\right)$ & - & $10^{-4-10^{-5}}$ & 0 & -9.6 & - & - \\
\hline $\mathrm{PbI}_{2}$ & $\begin{array}{l}4 \times 10^{-4}\left(0^{\circ} \mathrm{C}\right) \\
6 \times 10^{-4}\left(15^{\circ} \mathrm{C}\right)\end{array}$ & Hexagonal & " & $\begin{array}{l}0 \\
2 \\
8\end{array}$ & $\begin{array}{l}-9.8 \\
-15.6 \\
-17.7\end{array}$ & $\bar{z}$ & $\bar{E}$ \\
\hline $\mathrm{CuO}$ & $5 \times 10^{-6}\left(19^{\circ} \mathrm{C}\right)$ & Monoclinic & " & 0 & - & -17.0 & $\longrightarrow$ \\
\hline $\mathrm{CdO}$ & $5 \times 10^{-0}\left(20^{\circ} \mathrm{C}\right)$ & Cubic & " & 0 & - & -15.6 & - \\
\hline $\mathrm{ZnO}$ & $3 \times 10^{-6}\left(19^{\circ} \mathrm{C}\right)$ & Hexagonal & " & 0 & - & -22.0 & - \\
\hline
\end{tabular}


50\%の温度を読み取ってこれを液滴の大きさに対 応する平均凍結温度とみなし，液滴の直径の対数 に対して目盛るとその間の関係は第 8 図の如くで める。共に直線状でしかも互に並行に走ってい る。今回は実験例がこの二つに過ぎないのでこう いう関係が一般に成立するか否かについてい今後 にまたなければならないが，液滴が小さくなるに つれ凍結温度も降るとの結果は他の研究者 ${ }^{(7)}$ によ っても見出されている処である。

以上をまとめると第 1 表の如くで，懸濁粒子が 混在する場合には水滴は凍結し易くなるが，この 效果は沃化銀に於て最も著しく現われていること が認められる。

\section{附記}

第 4〜7 図の凍結曲線は下式によって表わされ る。いま, 過冷却度, 即ち, $0^{\circ} \mathrm{C}$ からの降下温度 数を $\theta$ とし, 過冷却度 $\theta$ 飞於汀る既凍結液滴の 数を $x(\%)$ とすると未涷結液滴の数は $100-x(\%)$ で，またこれらの各未凍結液滴の凍結の確率を $p=k \cdot(x / 100)$ と考皇るならば

$$
\frac{d x}{d \theta}=k \frac{x}{100}(100-x)
$$

が成立する。ここで $p=k \cdot(x / 100)$ は液滴の大きさ の他懸濁物質の種類及びその表面の性状等に依存 する量で，kはこれらが一定の場合，一定でめる。

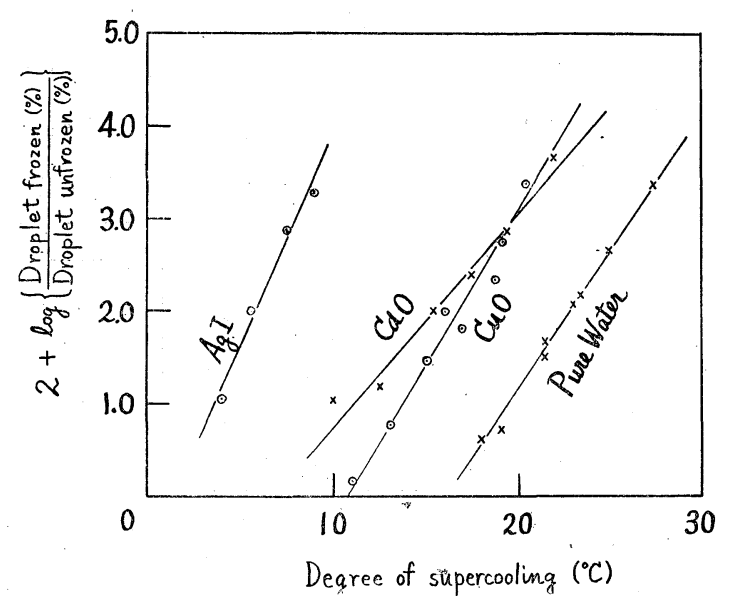

Fig. 9. Examples of plot of $\ln \{x /(100-x)\}$ as a function of $\theta$. The silver iodide line was obtained from the B curve of Fig. 5 and the water line from the $0.5-0.7 \mathrm{~mm}$ curve of Fig. 4 .
上式を積分すると

$$
\begin{gathered}
\ln \frac{x}{100-x}=k \theta-k \theta^{\prime} \\
\theta^{\prime} \text { : 凍結率 } 50 \% \text { の過冷却度 }
\end{gathered}
$$

従つて $\log \{$ 倲結液滴数(\%)/過冷液滴数(\%) $\} \sim \theta$ の 閒に直線関係が得られる筈であるが，実際乞の通 りであることは次の二，三の例に見られる処であ る(第 9 図)。

終りにのぞみ，本研究は中部電力株式会社の人 工降雨実験に関する基礎研究の一部として行なわ れたもので，同社より与えられた種々の援助に対 し謝意を表する。

\section{References}

1. Sano, I., Fujitani, Y., Itō, K. and Kitani, S. (1956): A Field Experiment of Snow-making by Seeding with Nickel Oxide, J. Met. Soc. Japan, 34, 185-189.

2. Schaefer, V. J. (1954): Silver and Lead Iodides as Ice-crystal Nuclei, J. Met., 11, 417-419; Birstein, S. J. (1954): Adsorption Studies of Heterogeneous Phase Transitions, Geophysical Res. Pap., No. 32 (Geophysics Res. Directorate, Air Force Cambridge Res. Center, Cambridge, Massachusetts, U.S.A.);

(1955): The Role of Adsorption in Heterogeneous Nucleation, I: Adsorption of Water Vapor on Silver Iodide and Lead Iodide, J. Met., 12, 324-331;

(1956): The Role of Adsorption in Heterogeneous Nucleation, II: The Adsorption of Water Vapor on Photolyzed Silver Iodide, J. Met., 13, 395-398;

Maruyama, H. (1956): Electron-Microscope Study of the Ice Crystal Nuclei, Pap. Met. Geophys., 7, 251-266.

3. Hosler, C. L. (1951): On the Crystallization of Supercooled Clouds, J. Met., 8, 326-331;

Maruyama, H. (1955): The Formation of Freezing Nuclei on a Plane, Pap. Met. Geophys., 6, 12-18;

Mossop, S. C. (1956): Sublimation Nuclei, Proc. Phys. Soc., B, 69, 161-164;

(1956): The Nucleation of Supercooled Water by Various Chemicals, ibid., 165-174; Isono, K. (1957): On ice-forming nuclei, J. Met. Soc. Japan, 35, 67-70.

4. 佐野惈, 福田矩彥 (1956): 沃化銀煙の水晶核と乙 ての安定度に及活す紫外線の照射並びに水蒸気, ア ンモニア等の添加の影響, 気象集誌, 34, 34-40; 佐野惈, 藤谷義保, 前名幸雄 (1956): 氷晶核に関 する実験的研究——種々の物質の核作用, 同上, 
104-110;

Sano, I. and Fukuta, N. (1956): Observations of the Ice-Nucleating Temperature of Some Chemical Substances, J. Met. Soc. Japan 34, 293-295;

佐野惈, 福田矩彥 (1957): 沃化銀の承晶核として の性質に及ぼす粒子半径, 温度及び混在油脂物質の 影響, 日本気象学会創立 75 周年記念論文集 (昭和 32 年), 25-31.

5. Itoo, K. and Hama, K. (1956): Freezing of Supercooled Water-droplets (I) - Preliminary Report, Pap. Met. Geophys., 6, 247-254;

Hama, K. and Itoo, K. (1957): Freezing of Supercooled Water-droplets (II), ibid., 7, 99-106; Komabayashi, M. (1957): On Freezing Temperatures of Supercooled Water Drops which
Contain a Melted Snow Crystal, J. Met. Soc. Japan, 35, 201-204.

6. 佐野惈 (1957): 煙霧質に関する最近の研究, 化学 と工業，10，272-280；

Drozin, V. G. (1955): The Electrical Dispersion of Liquids as Aerosols, J. Colloid Sci., 10, 158-164.

7. Bigg, E. K. (1953): The Formation of Atmospheric Ice Crystals by the Freezing of Droplets,

- Quart. J. Roy. Met. Soc., 79, 510-519:

Jacobi, W. (1955): Utber die Eisbildung in reinem Unterkühlten Wasser, Z. Naturf., 10a, 322330 ;

Hama, K. and Itoo, K. (1956): Freezing of Supercooled Water-droplets, Pap. Met. Geophys., 7, 99-106. 